\title{
An Ethnographic Study on the Linguistic Landscapes of the Coffee Shops in Songjiang University Town in Shanghai From the Perspective of "The Third Place"
}

\author{
Shiping Deng \\ Institute of Linguistics, Shanghai International Studies University, Shanghai, China
}

\begin{abstract}
This paper examines how coffee shops, as important public places, convey the owners' understandings of the socio-economic conditions by constructing meaning through linguistic landscapes. Coffee shops' features are further explored through a survey of the interactions or dialogues happening in these places. Qualitative Data are collected through an ethnographic study on the coffee shops in Songjiang University Town in Shanghai. The results indicate that the linguistic landscapes of these coffee shops construct a business-first ideology, and interactions or dialogues beyond time and space based on new media have replaced "coffee talk" and thus changed the characteristics of communication practice in these places. The paper concludes that the attributes of coffee shops as "the third place" have gradually faded in this increasingly commercialized society.
\end{abstract}

Index Terms - coffee shops, "the third place", linguistic landscape, business-first ideology, the decline of "coffee talk"

\section{INTRODUCTION}

Linguistic landscape is an important tool of meaning construction. The linguistic landscapes in public space can reveal the status of different languages and the users' ideology (Landry \& Bourhis, 1997). The scope of linguistic landscape research has been expanded from city streets and squares to other places such as libraries, churches, etc. The research foci have shifted from public signs to semiotic assemblages (i.e. material and semiotic resources such as environment, customers, goods and languages coming together). Recently, researchers have conducted detailed linguistic landscape studies on spaces of consumption such as shops, markets and stores (Zhu et al., 2017; Izadi, 2017; Pennycook \& Otsuji, 2017; Lou, 2017). As an important type of public space, coffee shops have also received researchers' attention recently. In order to get a through and comprehensive understanding, interdisciplinary methods have been applied. Researchers found that people from the middle class would go to coffee shops like Starbucks purposefully to distinguish themselves from the poor (Gaudio, 2003); consumption there is one type of "cultural habitus", which is used by the middle class as a strategy of "distinction" (Bourdieu, 1984). Another interesting finding was that in order to relieve their anxiety and maintain their positions in the socioeconomic pyramid, middle class Americans who label themselves as "considerate" consumers would try to build imagined connections between consumers and coffee farmers by paying attention to the lexicon of coffee. In so doing, farmers are put at a seemingly important position although actually the middle-class people know little about those hardworking laborers (Cotter \& Valentinsson, 2018). It can be seen that linguistic landscapes constructed by consumptions, pamphlets, websites and magazines may reveal complex social, political, or racial issues. However, most studies on the linguistic landscape of coffee shops have been conducted in the context of America. Coffee shops outside the USA have not been fully explored. Therefore, this study would focus on coffee shops in China and discuss the economic, social and cultural realities expressed by coffee shops situated in the highly commercialized metropolitan areas.

\section{II. "Dialogue” AND Coffee Shops as A “ThiRd Place"}

"Dialogue" is an important concept of Mikhail Mikhailovich Bakhtin's theory, which was initially used to express the relationship between the author and the readers of a literary composition. It prevailed afterwards in the interpretation of communication and gradually became profound philosophy. In the narrow sense, dialogue means face-to-face vocalized verbal interaction or communication. In a broader sense, however, it is more general and complex, meaning any type of verbal communication (Volosinov 1973: 95). In its broad sense, dialogue does not necessarily mean that all individuals involved must be on the spot, and the mode of communication can be vocalized or non-vocalized. Individuals living in different times or places could communicate or interact with each other as long as there is a common theme that is referred to, even if there is no actual utterance. The relevance of themes is critical to make dialogues which transcend time and space happen (Wang \& Pan, 2012). 
According to the American sociologist Ray Oldenburg, coffee shops are one type of "the third place". Oldenburg argues that aside from home and workplace, "a third place" - a generic designation for a great variety of public places that host the regular, voluntary, informal, and happily anticipated gatherings — is also indispensable to everybody. As Oldenburg describes, "the third places" are lively, scintillating, colorful, and engaging sites where good idle talks or relaxing and interesting "dialogues" happen. They are neutral places where consumers can find equality. The atmosphere there is free, open and pleasant, which is completely different from the formal and rigorous workplace. Moreover, consumers can get rid of the pressure from their homes. These common features of "the third place", according to Oldenburg, are extremely important to people's informal public life (Oldenburg, 1999). As a typical example of "the third place", coffee shops developed with the rise of capitalism and were regarded as ideal places for the spread of feminism and the free exchange of liberal thoughts (Gaudio, 2003).

Based on Bakhtin's definition of "dialogue" and Oldenburg's theory of "the third place", this study analyzed the linguistic landscapes of coffee shops by conducting an ethnographic study in Songjiang University Town in Shanghai, aiming at identifying how different linguistic landscapes help construct interactions or "dialogues" between the coffee shops and the consumers. The influences of these interactions or "dialogues" on the nature of the coffee shops as "the third places" were also explored.

\section{METHODOLOGY}

\section{A. Research Question}

Guided by Bakhtin's definition of "dialogue" and Oldenburg's theory of "the third place", this paper addressed the following two questions:

(1) How do coffee shops construct and express meaning through linguistic landscapes and other semiotic assemblages (Pennycook \& Otsuji, 2017)?

(2) What effects have linguistic and semiotic landscapes made on the nature of coffee shops as "the third places"?

\section{B. Data Collection and Data Analysis}

The researcher conducted surveys on different types of coffee shops (i.e. one international coffee shop-Starbucks, one famous Chinese coffee shop-Luckin, and three private ones) in Songjiang University Town in Shanghai from November of 2019 to December of 2020. Data of the environment, linguistic signs, dialogues and interactions inside the coffee shops were collected by participant observation, interviews, field notes, photos, audios, etc. All data were transcribed and analyzed by the researcher through three rounds of coding (i.e. open coding, pattern coding, and a final phase of clustering) until themes were identified (Saldaña, 2015). For ethic consideration, shop assistants and customers are addressed by codes instead of real names, and their faces in pictures were covered by mosaics. Information about the coffee shops is presented in Table I.

TABLE 1

THE COFFEE SHOPS' INFORMATION

\begin{tabular}{|l|l|l|}
\hline Coffee shops & Location & Scale \\
\hline Starbucks & No. 258, at Wenhui Road, Songjiang District, Shanghai, China & international, chain \\
\hline Luckin & No. 925, at New Songjiang Road, Songjiang District, Shanghai, China & Chinese, chain \\
\hline Muwei & No. 205, the 338th lane at Wenhui Road, Songjiang District, Shanghai, China & private \\
\hline Constellation & No. 219, the 338th lane at Wenhui Road, Songjiang District, Shanghai, China & private \\
\hline HANA & No. 17, the 166th lane at Wenhui Road, Songjiang District, Shanghai, China & private \\
\hline
\end{tabular}

\section{RESUltS}

\section{A. The Environment of Coffee Shops}

\section{Starbucks}

Observation results show that usually there are so many consumers in the coffee shop that not everybody can find a seat. The shop assistants are so busy that it is impossible to keep the tables clean and tidy. Interior decoration may be slightly changed according to different themes (what should be noted is that interior decoration basically remains the same). In November, 2019, for example, the theme was Charismas, which can be seen from the big picture on the wall and the nearby Christmas tree (Figure 1). At that time, Christmas was still one month away, but all kinds of Christmas elements were ready, which indicated the power of capital. 


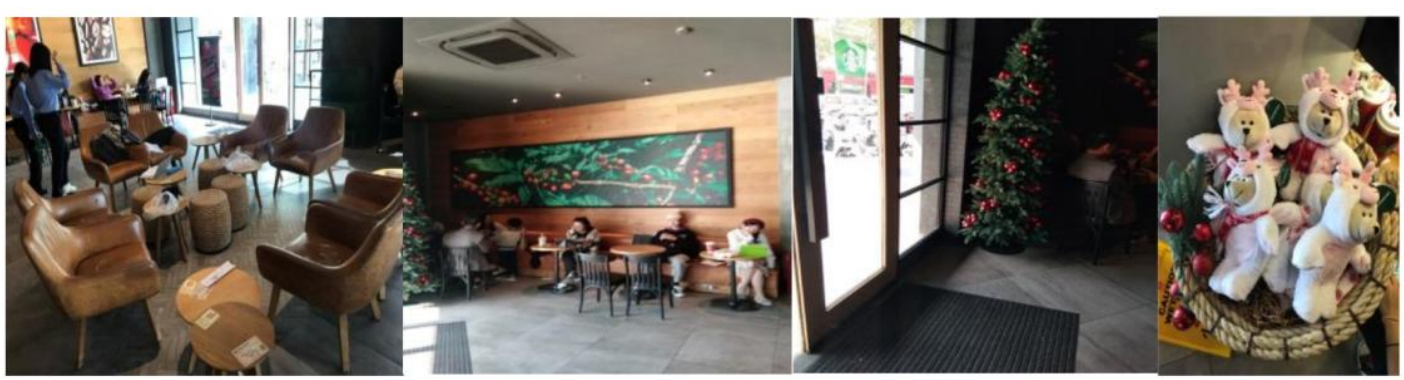

Figure 1. The Environment of Starbucks (1)

On the left side of the entrance there is always a bookshelf full of magazines with a consuming orientation. Few people pick up these magazines. One can find there are three pictures on another wall (these pictures are there all the year round) whose color, content and style are different from the above-mentioned picture under the theme of Christmas. The theme of these pictures is coffee, reminding the consumers that this is a coffee shop (Figure 2).

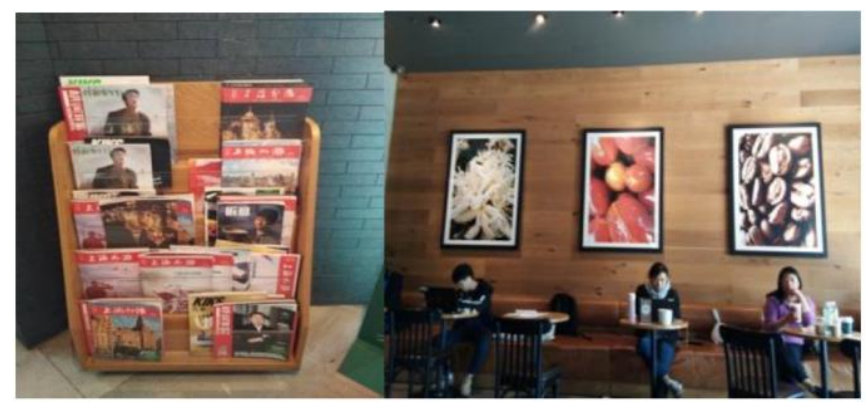

Figure 2. The Environment of Starbucks (2)

Surrounded by six couches, there is a round table in the middle of the coffee shop, where people can put their feet on and relax themselves. The lights on the ceiling always glow softly, creating a calm and warm atmosphere with the support of the window shade (Figure 3).

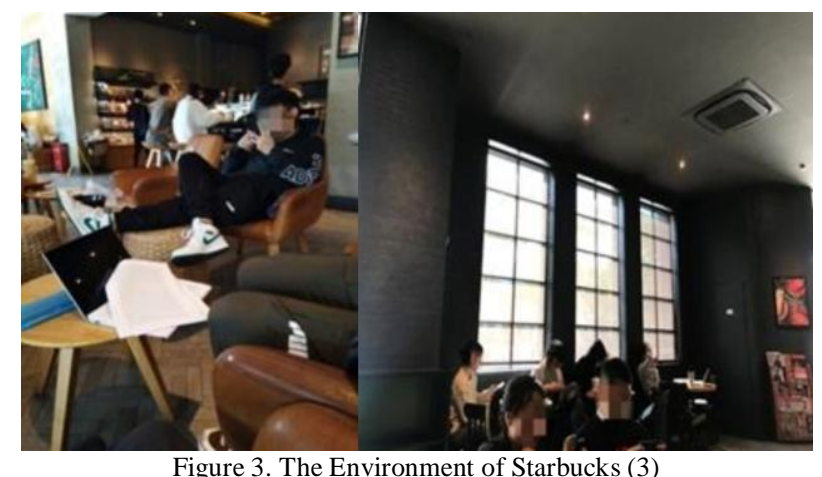

These symbols intend to create a homely, comfortable and artistic atmosphere. However, as a result of so many customers, the general impression is chaos. Starbucks always claims that consumers can enjoy coffee and comfort at the same time, but usually people may find themselves in the clamor of the "market". The sounds of different machines are noisy; the shop assistants are shouting all the time. Therefore, the coffee shop is always buzzing. It is difficult for one to find tranquility; peacefulness is a luxury here.

\section{Luckin}

Luckin is cramped; there are only three seats. It is more like a coffee "stall". Consumers cannot enjoy their coffee in the shop. Actually, its major business is takeout. Here everything is streamlined; the two shop assistants are always busy. The coffee machines and the air conditioner are so noisy that it is hard for people to have a natural conversation. There is no menu in the "stall", and consumers cannot place an order here (instead, orders are placed online). The service counter area is much larger than the space where consumers can wait or have a rest. There is a huge brand logo on the wall; closets (with built-in light) around the logo are full of coffee beans and ceramic cups which are presented in an elegant way. On the counter, the plastic bag for takeout are always ready for packing and a QR code for downloading the Luckin app is always available (Figure 4). 


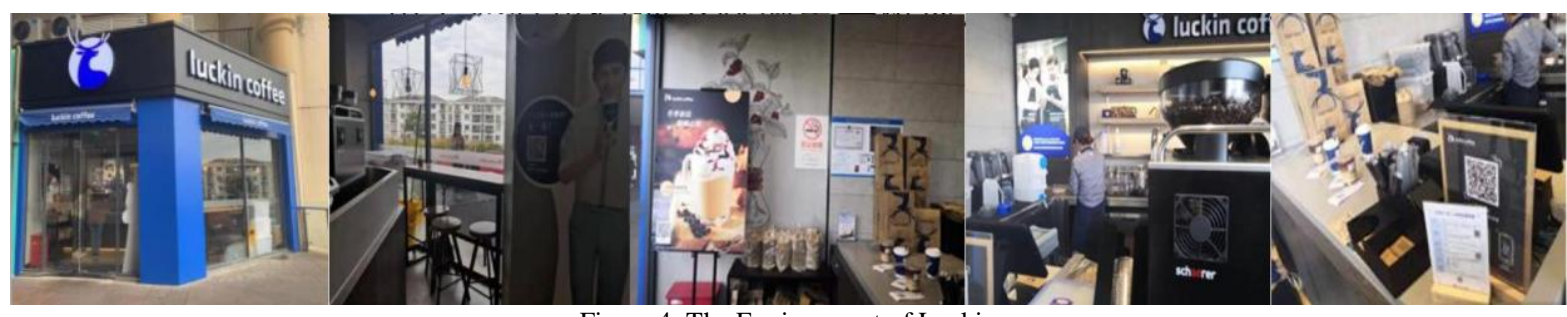

Figure 4. The Environment of Luckin

The environment of Luckin shows a conflict between elegance and disorder. On the one hand, the elegantly presented products in the closets and the built-in light are to bring consumers comfort and ease; on the other hand, however, the cramped space, the noisy environment, and the QR code tell everybody that here transactions are more important than anything else.

\section{Privately owned coffee shops}

The three privately owned coffee shops are rather inconveniently situated, possibly because of the rent. As for interior decoration, the three shops are very different from each other because the owners can make their own decisions based on their personal tastes. But there are still some common features: Firstly, the decoration is causal; there is no integrated style in each shop. Secondly, the environment inside is not very good: one can find handwritten tips on the wall, disordered wires on the ground, and other things banked up in the corner (Figure 5).
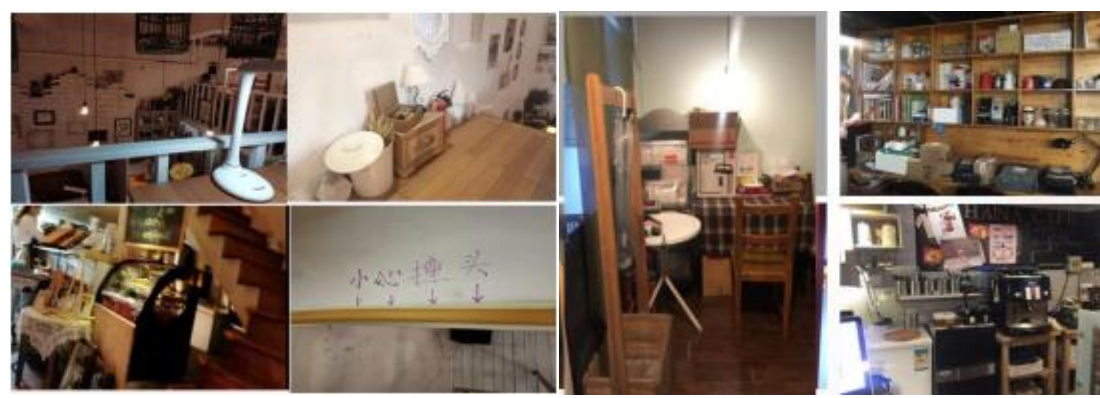

Figure 5. The Environment of the three privately owned coffee shops

\section{B. Static Linguistic Landscape in Coffee Shops}

\section{Starbucks}

The menus in Starbucks are bilingual. The English are put beneath the Chinese. The prices in Arabic numerals are more noticeable than the words. Big pictures of some products are also presented on the menus. So consumers usually place their orders by "reading" the pictures instead of the words. To the right of three major menus, there is a special menu advertising a special category — the "Taifei”. The handwritten Chinese sentence “太妃, 负责始终给你甜” (which means "Taifei can bring you sweetness") together with the English caption "MERRY COFFEE" can guide the consumers to make a connection between coffee and sweetness/happiness (Figure 6).

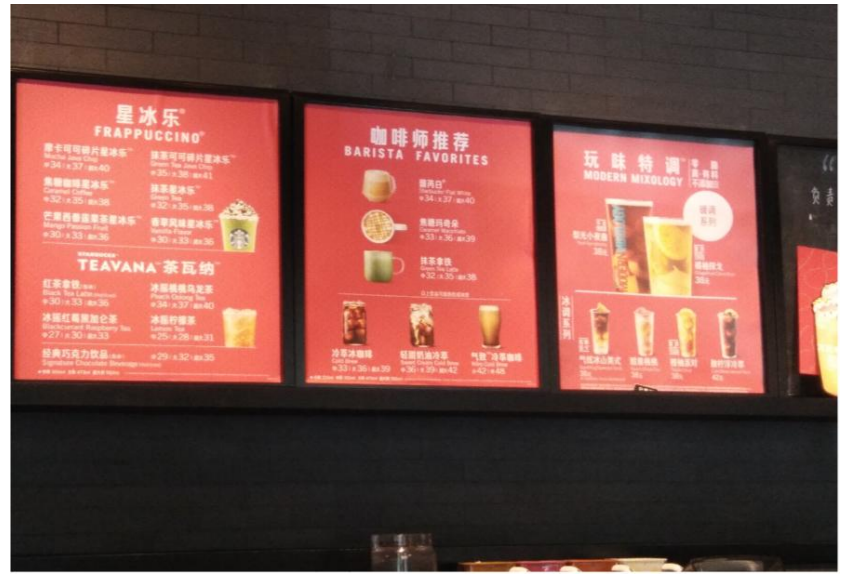

Figure 6. The menu at Starbucks

While Chinese are highlighted on the major menu, English letters or words dominate the other signs. For example, the English words "Starbucks Coffee" are put on the top of the receipts (without a corresponding Chinese version). On each receipt, the cashier's English name is also printed. Besides, the shop assistants' English names are also shown on their work clothes (Figure 7). 


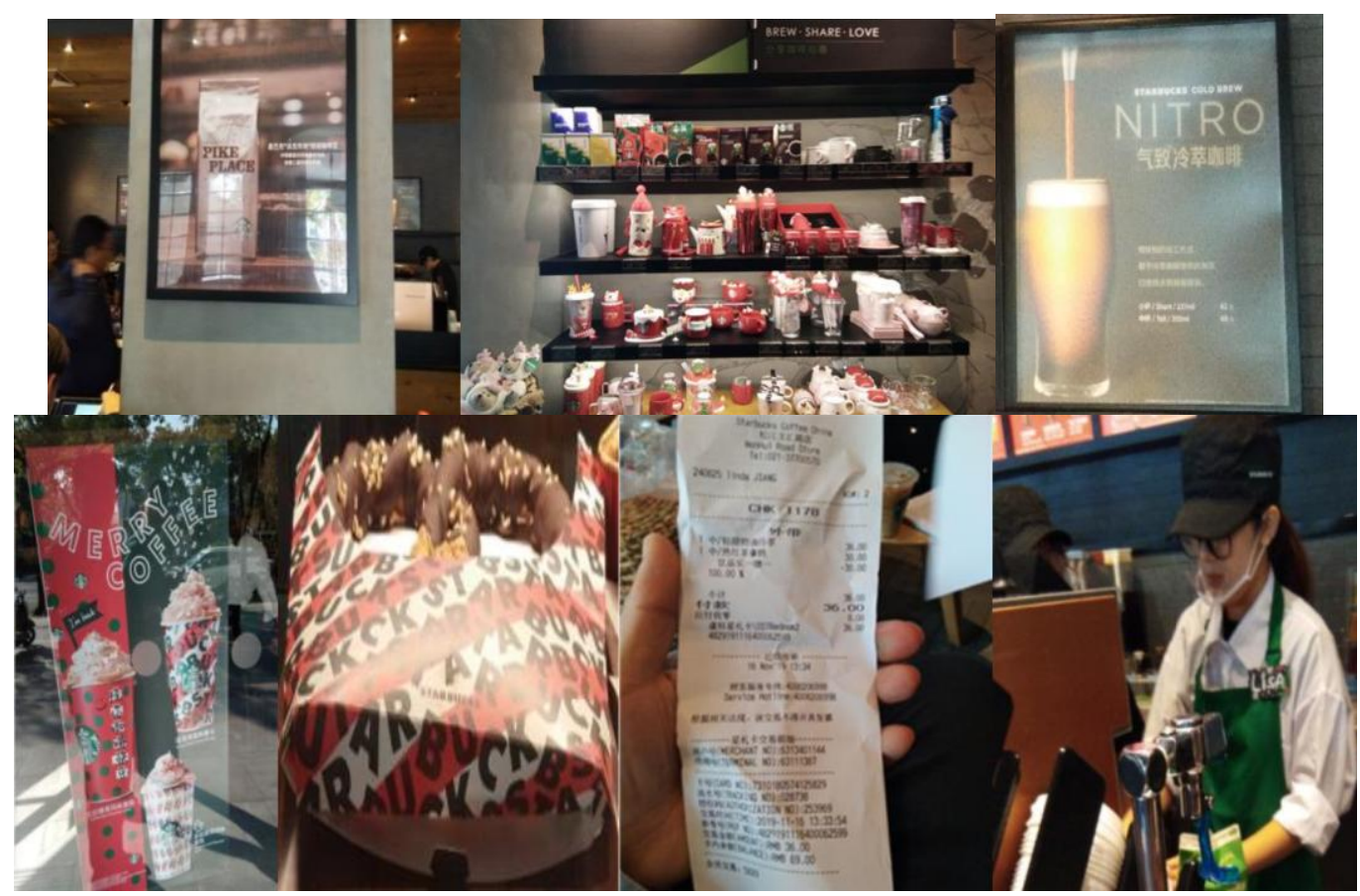

Figure 7. English dominates other signs at Starbucks

English letters and words also dominate the areas of exhibiting coffee beans and coffee kettles, which shows the great influence of the foreign language. The English-dominating reality may also reveal the ideology of the coffee shop - to establish an open and international image.

This ideology can also be revealed from the names of many other dishes. For example, the "Parmesan cheese toast" is intentionally labeled as "Italian Parmesan cheese toast", and "Brioche" is labeled as "French Brioche" (Figure 8). These westernized expressions are aimed at making the shop international and exotic. The ultimate goal is to persuade people to purchase. What can be seen from these names is the subtle relationship between language and consumption, or between language and people's economic life.

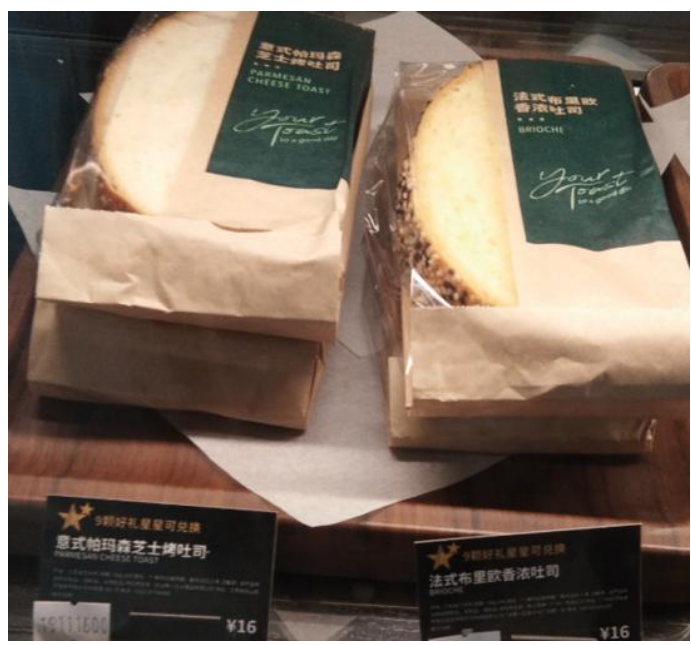

Figure 8. Names of some products at Starbucks

Another message one can get from the signs in Figure 8 is that the coffee shop switches to Chinese if the signs are directly related to consumers' decision to buy. This agrees with the status of Chinese in the major menus (Chinese is placed above English, Figure 6). The purpose of using Chinese in these circumstances is to catch people's attention as soon as possible and help consumers make the quickest decision to purchase. After all, according to the researcher's observation, most consumers in this coffee shop are Chinese.

What also needs to be noted is that QR codes are usually accompanied by Chinese expressions as captions, but the former is more noticeable than the latter (Figure 9). QR codes - semiotic landscapes in the electronic-payment era symbolize the increasing commercialization of the society. Moreover, according to the researcher's observation, the functions of QR codes have gone beyond payments. For example, next to one large QR code, there is a sentence: "Do you want to drink a cup of coffee? If you do not have time to wait in the queue, scan this code" (See the second picture 
in Figure 9). The sentence and the code indicate that pressure and time famine have been everywhere.
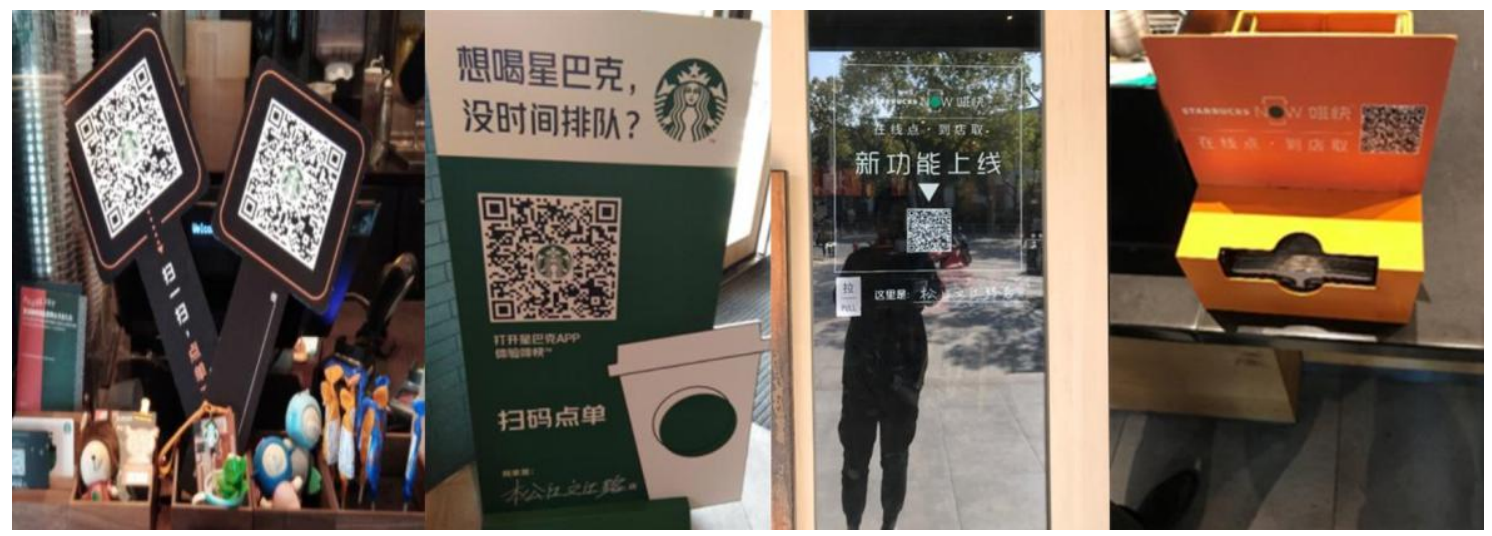

Figure 9. The QR code at Starbucks

Starbucks intends to create a "third place" and help people enjoy one moment of comfort. But linguistic landscapes such as "do not have time to wait in the queue" clearly indicate that people may feel pressed or time-stressed instead of enjoying the pleasure when they want to drink a cup of coffee (in the next section, more details about this will be presented). One more thing needs to be mentioned is that the new way of transaction - scanning a QR code, placing an order on line and fetching the coffee at the coffee shops - was firstly introduced by Luckin. Shortly afterwards, Starbucks followed. People may feel the air of "business war" through this semiotic landscape.

\section{Luckin}

The mode of Luckin is "ordering online, and fetching offline". Therefore, the researcher mainly focused on the static linguistic landscapes on the Luckin app (Figure 10). On the top of the app is a group of pictures which introduce the IIAC awards for the espresso recipe, the two stars of endorsement, and information on promotion and introduction to the new products. In the middle of app is a module of placing orders and depositing. Below this module is a chart of popular products and advertisements for snacks. At the bottom are some virtual buttons: "first-page", "menu", "popular products", "shopping cart", and "mine". The virtual menus on the app are bilingual, but the Chinese names of the products are more noticeable than the English names (the latter are in gray). These linguistic landscapes can reveal the transaction-first ideology.

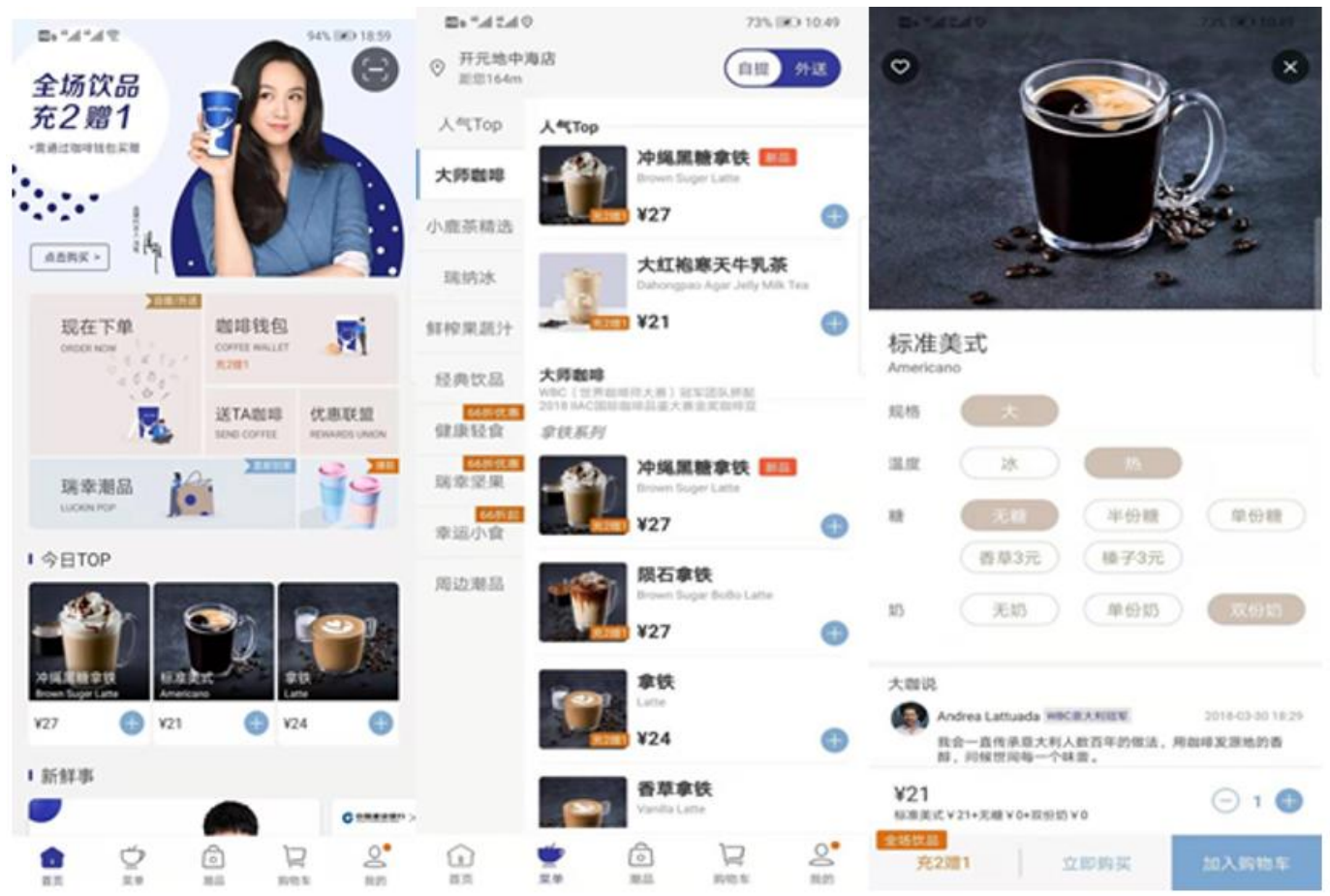

Figure 10. The static linguistic landscape of the Luckin app

Although the offline Luckin coffee shop is cramped inside, the English brand sign "Luckin coffee" outside is still large and noticeable. Besides, at the entrance there is always a big poster advertising its new products (Figure 4, the first and the second pictures on the left). All these reveal again the shop's marketing strategy and business-first orientation. 


\section{Privately owned coffee shops}

The menu of Constellation coffee shop is printed on loose-leaf kraft pages which are bound by small hoops. Some of the drinks or dishes are presented with pictures while the others are not. The menu is monolingual: one can only find Chinese on it. Each constellation corresponds with one product. The menu includes not only the names of the products, but also corresponding honeyed words, which is the special design (Figure 11). However, modifications were made by pen directly on the menu (instead of making another printed menu). Besides, the handwritten warning on the wall"mind your head" — also shows the shop owner's insouciance. Similar phenomena also appear in other privately owned coffee shops (Figure 12). Being exquisite and being causal coexist in these places.

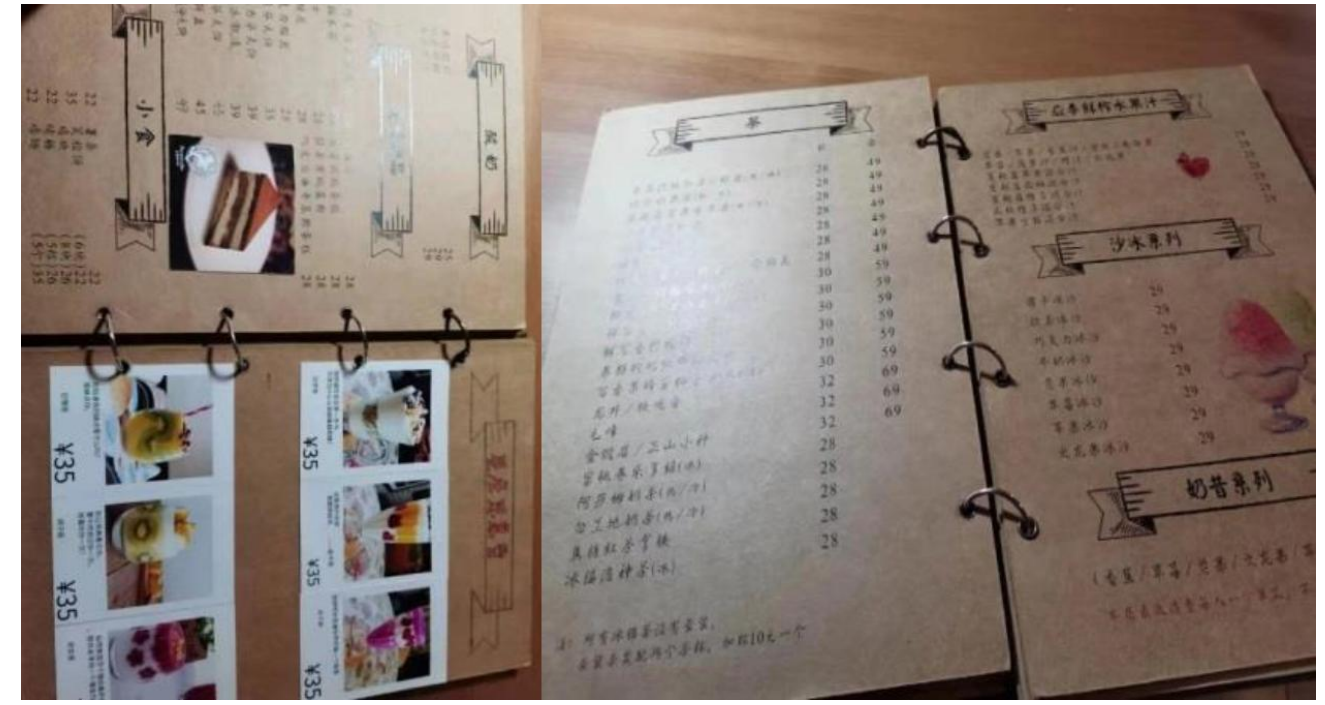

Figure 11. The menu at privately owned coffee shops (1)

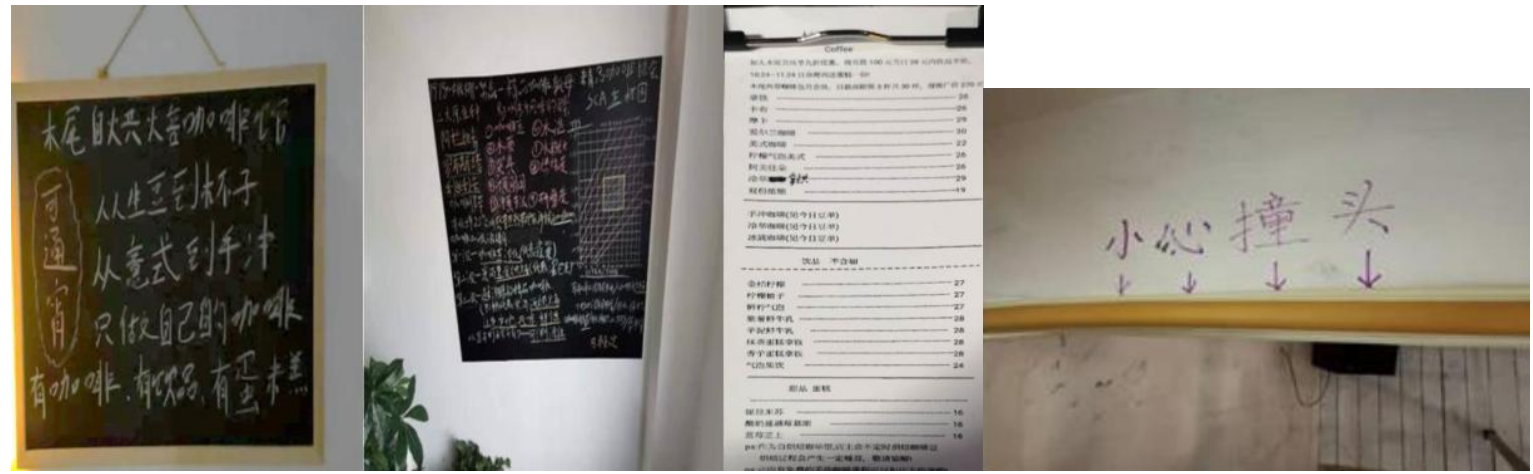

Figure 12. The menu at privately owned coffee shops (2) and warning written on the wall
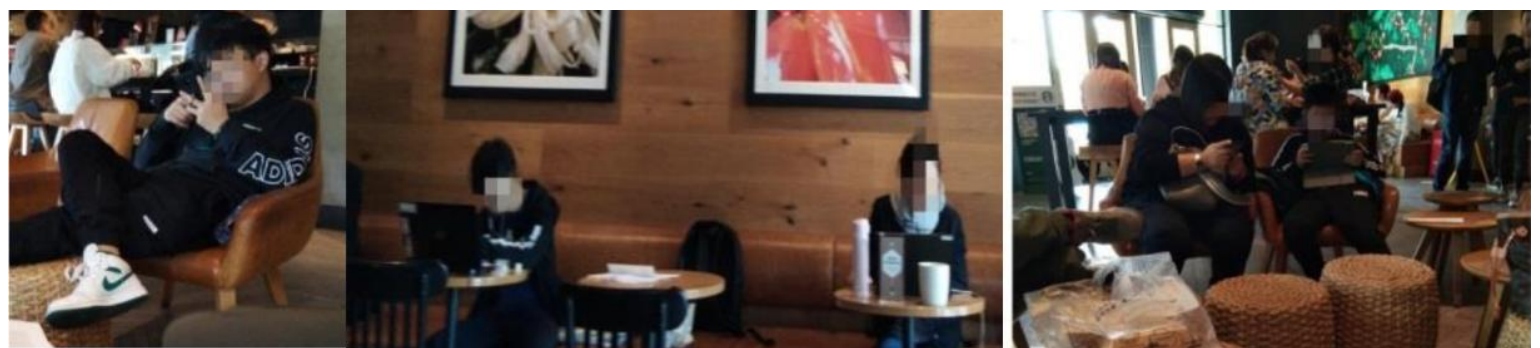

Figure 13. The activities and interactions between consumers at coffee shops

\section{Interactions or "Dialogues" in Coffee Shops}

\section{Interactions or dialogues between consumers}

This section reveals the activities and interactions between consumers. Firstly, many consumers bring their computers to coffee shops and make the coffee shop the second workplace. Secondly, cellphones and ipads are other important tools for consumers. A lot of consumers would spend much time on these media. Thirdly, the rest usually close their eyes for a while or make very short conversations with their companions. Therefore, the researcher would argue that "silence" becomes one of the most important linguistic landscapes in the coffee shops. For example, on one occasion, a mother and her son were spending their free time together in Starbucks. But they seldom had dialogues with 
each other because the mother was reading something on the cellphone while the son was playing video games via his ipad (Figure 13). They were so immersed in the respective virtual worlds created by the electronic media that the coffee shops seemed to become places of no importance.

\section{Interactions or dialogues between consumers and shop assistants}

All the shop assistants at the five coffee shops would say "hello ("ninhao" in Chinese)" when the consumers come into the shop. But aside from buying and selling, there is little interaction between consumers and shop assistants. Most of the time, shop assistants would repeat the following sentences:

"Ladies and gentlemen who are waiting in the queue can place orders through your cellphones."

"Who ordered two cappuccinos?"

"Is Miss Li here? Your coffee is ready."

"No. 5, please fetch your coffee."

In other circumstances, the shop assistants would give quick response to the consumers' questions, usually in a lower voice, with no facial expressions.

Sometimes there is even no direct interaction between consumers and shop assistants at all. In Luckin, for example, the researcher once saw the following scene: a lady who was talking via her Wechat, came in, scanned the QR code, went back to her talk, took her coffee and then left. She and the shop assistant spoke nothing to each other. Everything was done via internet and cellphones. Coffee shops did not become a place of daily conversation.

\section{Interactions or dialogues among shop assistants}

The researcher found that the dialogues among shop assistants also revolved around buying and selling. For example, at Starbucks, one assistant told her colleague, "Look, if you cooperate with me by holding the kettle in this way, we can be more efficient".

\section{DISCUSSION}

Research results indicate that linguistic landscape and other semiotic assemblages co-construct a consumption-first notion in "the third places", and the discourse practice between people of different identities in these shops in turn has changed the attributes of coffee shops as "the third places".

\section{A. Business-first Orientation}

Place semiotics argues that code preference, font size, letterform, the color, the arrangement of different codes can show the competition of different languages and the shop owners' personal ideology (Scollon \& Scollon, 2003). From the environment constructed by the various linguistic and semiotic landscapes, one can easily notice the business-first orientation: the ultimate purpose of the shops is to attract more consumers, and the noise, clamor, and muddle are the representations of the ubiquitous commercial atmosphere. For example, English is seemingly ubiquitous, but it is still one tool of the shop owners to construct exoticism or an internationalized image. When it comes to consumption and capital (i.e. buying and selling), English would give way to Chinese because the consumers need to understand the exact information through their native language in order to get a deal done. As is mentioned above, Chinese is more noticeable than English on the menus and apps. From the interactions and conversations, one can see that coffee shops pay more attention to the efficiency (of purchasing, especially) than to the good relationship between the shop and the consumers. Shop assistants focus on profits: although they show politeness to consumers, there are no exchanges of feelings and thoughts. Consumers are even addressed as numbers or codes. The conversations among shop assistants, or the conversations between consumers and shop assistants are generally short; once a transaction is complete, the purpose of communication is also achieved.

\section{B. Disillusionment of "the Third Place"}

Capital is represented by different semiotic and linguistic landscapes in the highly commercialized coffee shops. The equality, comfort and tranquility have now been replaced by the noise and clamor of coffee chains or by the disorder of privately owned coffee shops. Owners of the coffee shops convey consumerism through environment construction and the static linguistic landscapes. They turn the shops into places of consumption. Coffee shops would gradually lose their attributes as "the third places".

The fading away of coffee shops as "the third places" are not just a result of the business-first orientation; it is also constructed gradually in the new ways of communication. Computers, cellphones, and "silence" gradually dominate these shops. Consumers just regard these shops as places where they can work or build up other trans-space or virtual relationships through the Internet. Coffee shops are no longer "the third places", and conversations revolving around or relevant to the context of traditional coffee shops seldom occur. In a word, the development of new media has greatly changed people's modes of communication and made huge impacts on the attributes of coffee shops as "the third places".

\section{CONCLUSIONS}

Through an ethnographic study of the linguistic and semiotic landscapes of the coffee shops in Songjiang University Town in Shanghai, this research concludes that the traditional coffee talk (Gaudio, 2003) is now fading away. The 
functions of coffee shops have been changing in the new context. The business-first orientation influenced by neoliberalism has made consumption become a critical need and a dominant notion in this era of commercialization. The socio-cultural conditions in coffee shops thus have been reconstructed revolving around business and capital. Coffee shops are losing their attributes as "the third places". Besides, new media like cellphones gradually dominate the interactions in these places; internet has made nonverbal and trans-space communication possible. In this circumstance, coffee shops' traditional cultural attributes have given way to their physical attributes as places of consumption. The traditional coffee shops as "the third places" are very likely to disappear in the future.

\section{ACKNOWLEDGMENTS}

The authors wish to thank the participants for their assistance in this research.

\section{REFERENCES}

[1] Bourdieu, P. (1984). Distinction: A Social Critique of the Judgement of Taste. Cambridge, Massachusetts: Harvard University Press

[2] Cotter, W. M., \& Valentinsson, M. C. (2018). Bivalent class indexing in the sociolinguistics of specialty coffee talk. Journal of Sociolinguistics, 22(5), 489-515. doi:10.1111/josl.12305.

[3] Gaudio, R. P. (2003). Coffeetalk: Starbucks ${ }^{\mathrm{TM}}$ and the commercialization of casual conversation. Language in Society, 32(05), 659-691.

[4] Izadi, D. (2017). Semiotic resources and mediational tools in Merrylands, Sydney, Australia: the case of Persian and Afghan shops. Social Semiotics, 27(4), 495-512.

[5] Landry, R., \& Bourhis, R. Y. (1997). Linguistic landscape and ethnolinguistic vitality: an empirical study. Journal of Language and Social Psychology, 16(1), 23-49.

[6] Lou, J. J. (2017). Spaces of consumption and senses of place: a geosemiotic analysis of three markets in Hong Kong. Social Semiotics, 27(4), 513-531.

[7] Oldenburg, R. (1999). The Great Good Place. Cambridge: Da Capo Press.

[8] Pennycook, A., \& Otsuji, E. (2017). Fish, phone cards and semiotic assemblages in two Bangladeshi shops in Sydney and Tokyo. Social Semiotics, 27(4), 434-450. doi:10.1080/10350330.2017.1334391.

[9] Saldaña, J. (2015). The Coding Manual for Qualitative Researchers. 3rd ed. London: SAGE Publications.

[10] Scollon, R., \& Scollon, S. (2003). Discourse in Place: Language in the Material World. London: Routledge.

[11] Volosinov, V. N. (1973). Marxism and the Philosophy of Language (L. Matejka, \& I. R. Titunik, Trans.). New York and London: Seminar Press.

[12] Zhu, H., Li, W., \& Lyons, A. (2017). Polish shop(ping) as Translanguaging Space. Social Semiotics, 27(4), 411-433.

Shiping Deng was born in Qingdao, Shandong Province in 1986. He received his master degree in Nanjing Forestry University, China in 2011.

$\mathrm{He}$ is currently a lecturer, and a Ph. D candidate in the Institute of Linguistics at Shanghai International Studies University, China.

His research interest: foreign language education, language policy and language planning, linguistic landscape. 